\title{
A tale of two countries: Rethinking sexual risk for HIV among young people in South Africa and the United States
}

\author{
Audrey E Pettifor ${ }^{1,2}$, Brooke A. Levandowski ${ }^{1}$, Catherine MacPhail ${ }^{2}$, William C. Miller ${ }^{1,3}$, \\ Joyce Tabor ${ }^{4}$, Carol Ford ${ }^{5}$, Cheryl R. Stein ${ }^{6}$, Helen Rees ${ }^{2}$, and Myron Cohen ${ }^{1,3}$ \\ ${ }^{1}$ Department of Epidemiology, University of North Carolina, Chapel Hill, NC, USA \\ ${ }^{2}$ Reproductive Health and HIV Research Unit, University of the Witwatersrand, Johannesburg, \\ South Africa \\ ${ }^{3}$ Division of Infectious Diseases, School of Medicine, University of North Carolina, Chapel Hill, \\ NC, USA \\ ${ }^{4}$ Carolina Population Center, University of North Carolina, Chapel Hill, NC, USA \\ ${ }^{5}$ Division of General Pediatrics and Adolescent Medicine, and Department of Pediatrics, School \\ of Medicine, University of North Carolina, Chapel Hill, NC, USA \\ ${ }^{6}$ Department of Preventive Medicine, Mount Sinai School of Medicine, New York, USA
}

\begin{abstract}
Purpose-To compare the sexual behaviors of young people in South Africa (SA) and the United States (US) with the aim of better understanding the potential role of sexual behavior in HIV transmission in two countries with strikingly different HIV epidemics.
\end{abstract}

Methods-Nationally representative, population-based surveys of young people ages 18-24 from SA $(n=7,548)$ and the US $(n=13,451)$ were used.

\begin{abstract}
Results-The prevalence of HIV was $10.2 \%$ in SA and $<1 \%$ in the US. Young women and men in the US reported an earlier age of first sex than those in SA (mean age of coital debut for females: US (16.5), SA (17.4); for males: US (16.4), SA (16.7)). The median number of lifetime partners is higher in the US than in SA: Females: US (4), SA (2); Males US (4), SA (3). Reported condom use at last sex is lower in the US than SA: Females: US (36.1\%), SA (45.4\%); Males: US $(48 \%)$, SA (58\%). On average, SA young women report greater age differences with their sex partners than young women in the US.
\end{abstract}

Conclusions-Young people in the US report riskier sexual behaviors than young people in SA, despite the much higher prevalence of HIV infection in South Africa. Factors above and beyond sexual behavior likely play a key role in the ongoing transmission of HIV in South African youth, and must be urgently uncovered to develop maximally effective prevention strategies.

\footnotetext{
(C) 2010 Society for Adolescent Medicine. Published by Elsevier Inc. All rights reserved.

Corresponding Author: Audrey Pettifor Department of Epidemiology CB \#7435, McGavran-Greenberg Bldg. University of North Carolina at Chapel Hill Chapel Hill, NC 27599-7435 Phone: (919) 966-7439 Fax: (919) 966-2089 apettif@email.unc.edu.

Publisher's Disclaimer: This is a PDF file of an unedited manuscript that has been accepted for publication. As a service to our customers we are providing this early version of the manuscript. The manuscript will undergo copyediting, typesetting, and review of the resulting proof before it is published in its final citable form. Please note that during the production process errors may be discovered which could affect the content, and all legal disclaimers that apply to the journal pertain.
} 


\section{Background}

South Africa (SA) is one of the countries most severely affected by the HIV epidemic. Among South African young people age 15-24 years more than $15 \%$ of young women and close to 5\% of young men are infected with HIV; 1 in comparison, less than $1 \%$ of young women and men are infected in the United States (US). 2 This great variation in HIV prevalence between Africa and the "West" has perplexed researchers since the beginning of the AIDS epidemic. Given that the vast majority of infections in sub-Saharan Africa are the result of heterosexual transmission, popular opinion has continued to foster the belief that the HIV epidemic in Africa is fueled by promiscuous sexual behavior $3^{-5}$, or unique sexual mixing patterns. $6^{-} 8$

Using data from nationally representative, population-based studies of young people age 18-24 years in the United States and South Africa, we aim to describe the sexual behaviors of young people in both countries to determine whether differences in sexual behavior can explain the enormous disparity in the HIV epidemics observed in the two populations. This is the first study comparing nationally representative samples of young people in both a high and low HIV prevalence country.

\section{Methods}

Data were obtained from two nationally representative samples, the Reproductive Health and HIV Research Unit (RHRU) South African Youth Survey and the National Longitudinal Study of Adolescent Health (Add Health). The methods of both studies have been described in detail elsewhere (Appendix A).1² Briefly, the RHRU South African Youth Survey is a nationally representative, cross-sectional household survey of youth aged 15-24 years in South Africa that was conducted from March to August 2003. The survey's sample was identified using a three-stage, disproportionate, stratified design. The 2001 national census was used as the sampling frame and enumeration areas (EAs) were designated as the primary sampling units. Households within selected EAs were enumerated and one eligible youth per household was randomly selected to participate in the study. The response rate was $69 \%$ with non-responders more likely to be male, white, older, and to live in an urban area. The behavioral interview was an interviewer-administered questionnaire conducted in one of nine languages. All questionnaires were translated from English into the local languages and then back translated. HIV testing was conducted among all participants. To make the sample comparable to the Add Health Wave III population, this analysis is restricted to young people aged $18-24$ years $(n=7,548)$.

Add Health is a longitudinal cohort study in the US. Add Health follows a systematically drawn, nationally representative sample of young people who were attending school in the US and in grades 7-12 during September 1994 through December 1995. Wave I was conducted in 1994-95, Wave II was conducted in 1996, and Wave III in 2001 and 2002. Wave III participants, aged 18-24 years $(\mathrm{n}=13,451)$ were all tested for HIV. This analysis uses data from Wave III which includes all original (Wave I) participants who were located and re-interviewed (77.4\% response rate) for Wave III.9 The majority of non-response was due to an inability to locate participants and refusal to participate once found.10 Nonrespondents were more likely to be male, older age in Wave I, black, urban, and from the Northeast. All interviews were conducted using computers; the respondent personally entered more sensitive information in private.

HIV testing in South Africa and the US was conducted using oral fluid samples collected using the Orasure ${ }^{\circ}$ HIV-1 Oral Specimen Collection Device (Orasure Technologies Inc., Bethlehem, PA). Samples were tested for HIV-1/2 antibodies using the Vironostika Uni- 
Form II HIV-1/2 plus O MicroElisa System (Biomerieux, Durham, NC) for South Africa and tested for HIV-1 antibodies using the Oral Fluid Vironostika HIV-1 Microelisa System (Organon Teknika Corp, Durham, NC) for the American samples.

\section{Statistical Analyses}

Key questions relating to sexual health and HIV risk were identified in the South African questionnaire and comparable questions were then identified from Add Health (Appendix B).

Descriptive statistics using unweighted counts and weighted proportions were calculated for key variables in both datasets. Analyses were conducted using STATA 9.0 (College Station, TX) allowing for sample strata, primary sampling units and population weights, utilizing appropriate techniques for analyzing a subpopulation within a survey sampling frame. This results in population-based estimates of behaviors among young people in each country, referred to as weighted estimates throughout the paper. We present weighted proportions of young people engaged in behaviors linked to risk of HIV in each country for descriptive comparisons. For some key measures (proportion of young people reporting ever having had sex; mean age of first sex; mean number of lifetime sex partners; use of condoms at last sex; mean partner age difference) we compared the two populations using a large sample t-test approximations with unequal variance assumptions based on the observed mean and variance of the specific measures. However, interpretation of these tests must be made cautiously. Each population survey was designed with a distinct target population, supporting a qualitative, rather than a statistical comparison. Further, the sample sizes of these two studies are large, which substantially increases the power to demonstrate significant differences. Thus we believe emphasis should be given to the actual estimates and whether the observed differences are meaningful from a public health perspective. Analyses were conducted for all youth, stratified by gender, and examined by age.

\section{Findings \\ Demographics}

The mean age of the South African young women and men were 20.7 and 20.6 years, respectively, while the mean age of the US young women and men was 21.5 and 21.6 years, respectively. As a marker of socio-economic status, we compared the reported educational level of the young person's mother. Among South Africans, $61.3 \%$ of young women and $57.3 \%$ of young men reported that their mothers had completed high school or greater while in the US $72.7 \%$ of young women and $82.7 \%$ of young men reported that their mothers had completed high school or greater.

\section{HIV Prevalence}

HIV prevalence in young women ages 18-24 in South Africa was 207.5 per 1,000 (95\% CI 168.60 - 246.47) while among young women in the US it was 0.87 per $1,000(95 \%$ CI 0.26-1.83). In young South African men ages 18-24 years HIV prevalence was 58.2 per 1,000 (95\% CI 47.35-69.10) and among young men in the US the prevalence was 1.06 per 1,000 (95\% CI 0.25-2.19).

\section{Levels of Sexual Experience}

The majority of young women ages 18-24 in South Africa and the US report having had vaginal sex, 84.4\% (95\%CI 82.3-86.4) and 87.9\% (95\%CI 86.6-89.2), respectively (p $<0.001)$. South African women report a later age of first sex compared to their American counterparts, 17.4 years versus 16.5 years $(\mathrm{p}<0.001)$. This is reflected by the fact that less than $65 \%$ of South African women report having had sex by the age of 18 compared to 
$71.4 \%$ of American women. In addition, early age of first sex (age 14 or younger) was reported by $4.6 \%$ (95\%CI 3.6-5.7) of South African women compared to $19.4 \%$ (95\%CI 17.7-21.1) of American women (Figure 1). Similar to their female peers, the majority of South African and American young men in this age group report being sexually experienced with more American young men reporting being sexually experienced than South African men [86.0\% (95\%CI 84.5-87.5) and 81.9\% (95\%CI 79.2-84.6) respectively, $\mathrm{p}<0.001]$. The average age at first sex for young men in South Africa and the US was 16.7 and 16.4 years respectively, $\mathrm{p}=0.04$. This difference is noted when examining the distribution of age of coital debut; more US men report an early age of coital debut compared to South African men (Figure 1).

\section{Number of Sexual Partners}

The mean number of lifetime sex partners reported by young women was 2.4 for South African women and 5.7for US women ( $\mathrm{p}<0.001$ ), with ranges of 1 to 90 partners and 1 to 50 partners, respectively. As shown in Figure 2, more South African than US girls report having only one lifetime partner; 35.1\% (95\% CI 30.5-39.7) of South African women reported having one lifetime partner compared to 21.1\% (95\%CI 19.4-22.9)of American women. More American than South African young women report having 10 or more lifetime partners. Among young men, the mean number of lifetime partners was 5.2 and 7.1 for South Africans and Americans, with ranges of 1 to 80 and 1 to 50, respectively, $\mathrm{p}<0.01$ (Table 1). More US young men reported having 10+ partners compared to South African men [23.2\% (95\%CI 21.4-25.0) versus 12.5\% (95\% CI 9.9-15.0)] (Figure 2).

\section{Partner Age Mixing}

On average, the age of the most recent sexual partner for South African women was 4.0 years older while American women had partners that were 2.6 years older $(\mathrm{p}<0.01)$. Although fewer than $10 \%$ of young women in South Africa and the US have partners ten or more years their senior [8.4\% (95\% CI 7.0\%, 9.8\%) and 5.1\% (95\% CI 4.3-5.9 respectively], overall more South African women had an older partner than American women. Thirty percent of American women (95\% CI 28.7-32.1) reported having a partner that was the same age or younger than themselves compared to only $8.2 \%$ (95\%CI 6.5\%, 10.0\%) of South African women (Figure 3). Almost 90\% (95\%CI 87.9\%, 92.2\%) of South African men and 75\% of American men (95\% CI 72.9-76.6) reported that their most recent sexual partner was the same age or younger than themselves (Figure 3). Of those South African men reporting a sexual partner the same age or younger, $14.4 \%(95 \% \mathrm{CI} 11.0 \%, 17.9 \%)$ were the same age, $52.8 \%(95 \% \mathrm{CI} 49.0 \%, 56.7 \%)$ were $1-2$ years younger, $29.7 \%(95 \% \mathrm{CI} 26.9 \%, 32.5 \%)$ were $3-5$ years younger and $3.1 \%(95 \% \mathrm{CI} 1.7 \%, 4.5 \%)$ were more than 5 years younger. Of those American men reporting a sexual partner the same age or younger, $33.0 \%(95 \% \mathrm{CI}$ 30.4-35.6) were the same age, $49.0 \%$ (95\% CI 46.4-51.5) were 1-2 years younger, $17.0 \%$ (95\% CI 15.1-18.9) were 3-5 years younger and $1.0 \%$ (95\% CI 0.4-1.5) were more than 5 years younger.

\section{Condom Use}

Condom use at last sex was reported by more South African than US women; among sexually active youth, $45.4 \%$ (95\% CI 41.6\%, 49.2\%) of South African women and 36.1\% (95\% CI 34.0-38.1) of US women reported using a condom at last sex $(\mathrm{p}<0.01)$ (Table 1). Among sexually active young men, 58\% (95\%CI 51.3\%, 64.7\%) of South African and $48.0 \%$ (95\% CI 45.6-50.4\%) of US young men reported using a condom at last sex $(\mathrm{p}<0.001)$. 


\section{Discussion}

Overall, the proportion of American youth reporting riskier sexual behavior (e.g. more sex partners, less condom use and earlier age of coital debut) is consistently higher than among their South African counterparts. Our results strengthen an accumulating body of evidence which finds that the sexual behaviors of individuals living in countries with generalized HIV epidemics are not higher risk than those of individuals living in countries with low HIV prevalencesepidemics.11-14 While sexual behavior(s) is a key determinant of HIV infection, factors that affect the probability of HIV transmission (i.e., viral load, STIs, circumcision) and the existing high background prevalence of HIV may be the key drivers for the continued heterosexual spread of HIV in South Africa. Prevention programs should thus focus greater resources and attention to factors beyond individual level sexual behaviors.

One difference we observed was that young South African women and men reported larger age differences with their most recent sex partners than US women and men. Despite this, few women in South Africa or the US reported having a partner who was significantly older (i.e. 10 or more years older). Age mixing between older and younger age groups has been cited as an important driver of the HIV epidemic, with infected older individuals acting as bridge populations whereby disease is spread to younger uninfected groups.7, $15 \mathrm{In}$ addition, greater gender power disparities between young women and their older male partners makes it more difficult for women to negotiate safer sex.16 Our research in South Africa has found that having a partner only 1-4 years older increased young women's risk of HIV infection.1 It seems, therefore, that even subtle age differences between partners may impact HIV risk, particularly if it results in sexual mixing with age groups that have a high prevalence of HIV infection.

South African men and women reported fewer lifetime sex partners compared to their US peers. Historically there has been a general perception that African men are more promiscuous than their Western counterparts. However, cultural norms advocating and condoning multiple partnerships as instrumental to a successful male identity are common in both Africa and the West.17-20 Similarly, a recent review of sexual behaviors from 59 countries found that the reporting of multiple sex partners was more common in developed than in developing countries.13 Although major differences in partner numbers between both countries are not apparent, it is possible that South African youth practice more concurrency than their US counterparts. We were unable to examine this issue. Concurrent partnerships appear to increase HIV transmission through populations to a far greater extent than serial monogamous relationships.11,21

The mean age of first sex among youth in South Africa and the US is similar to that observed worldwide.13 In fact, we found that more US men and women reported their first sexual experience at age 14 or younger compared to their South African peers. Early age of first sex has been reported as a risk factor for HIV infection6, $22^{-2} 25$ and increasing the age of first sex is the focus of many HIV prevention campaigns.26-27 While this is an important and laudable goal, it must be recognized that its effectiveness in preventing HIV in high prevalence countries may be quite limited.28 This is salient given that many young people, particularly young women, do not control the terms and conditions of sexual relationships and many first sexual experiences are unwanted or forced.18, 29-30

Condom use at the most recent sex act was reported by more South African than US youth. Global trends of increasing condom use are mirrored in South Africa; the 1998

Demographic and Health Survey reported that only $16.6 \%$ of sexually active women used a condom at last sex compared to the proportion reported from this survey (45.4\%).31 Despite reported increases in condom use at last sex, consistent condom use in South Africa remains 
low, 1 and therefore still allows for HIV transmission. Similar to what is observed in many countries, 13 young men reported using condoms more than their female peers; likely the result of gender power dynamics and the fact that men report having more casual partners than women and are more likely to use condoms during these sexual encounters.13

In South Africa where at least one in ten individuals is infected with HIV, the risk of coming into contact with an infected partner is far greater than in the US where the risk is approximately one in 1000 (although the risk is skewed and higher for particular sub-groups of the population).2 This high prevalence of infection in the general South African population means that young people do not have to engage in high risk behaviors (i.e., multiple partners, lots of unprotected sex) to be at risk for HIV infection. Certainly sexual behavior is an essential element of HIV risk, nevertheless, high risk behavior may not be a prerequisite for HIV transmission.

Our findings support the hypothesis that factors which increase the probability of HIV transmission or acquisition may play a greater role in the continued spread of the epidemic in young susceptible populations than heretofore appreciated. Some of these factors were not measured in both surveys, but could partially explain disparities in the epidemics. High rates of STI, in particular HSV-2, have been found among youth in South Africa32-33 and among African American young people in the US.34 Circumcision has recently been found to significantly reduce the risk of HIV acquisition in men.35-37 Rates of circumcision in the US are between 55-65\%,38 while approximately only one-third of young men in South Africa are currently circumcised.1

\section{Study Limitations}

Both surveys relied on self-reported sexual behavior and may therefore be subject to socialdesirability bias, resulting in over-reporting of some behaviors and under-reporting of others. Both countries have different cultural contexts and norms that influence what is deemed socially desirable with regard to sexual behavior. In addition, the US survey was conducted using a mode that offered more privacy than the SA survey which could have resulted in US respondents feeling more comfortable reporting socially undesirable behaviors than their SA peers. While some of the differences in reported behaviors between genders and countries may be a function of social desirability bias, certainly there are also true differences in behavior that are products of different cultures and contexts that encourage or dissuade particular sexual behaviors, and their reporting. Other limitations of these surveys include selection bias and non-response, which may result in the selected populations being at higher or lower risk than the total youth population in each country. As shown in Appendix B, many variables of interest were assessed by asking similar questions, resulting in comparable covariates. Other concepts of interest, such as forced sex, were asked differently in the two questionnaires, limiting the ability to compare these selfreported behaviors across populations. Further, the prevalence of several potentially important risk factors (anal sex, same sex partner, injection drug use) were too low for inclusion in this analysis. In addition, we were unable to compare factors such as concurrency, male circumcision and HSV-2 which may explain some of the differences observed in epidemics between the two countries. We were unable to directly compare factors associated with prevalent HIV infection in each country given the low number of HIV infections observed in the US sample.

\section{Conclusions}

Effective HIV prevention strategies demand an accurate perception of the spread of HIV. The results of this study demonstrate that the remarkable prevalence of HIV in young people in South Africa cannot be ascribed to exceptional risk taking behavior. Indeed, it seems clear 
that when HIV achieves the high population prevalence found in much of sub-Saharan Africa, 'common' sexual behaviors lead to exceptionally high risk of HIV acquisition. Unique biological forces must be playing a role as well. Accordingly, successful HIV prevention in these populations will require extraordinary efforts that more clearly convey the risk involved in routine sexual behavior, as well as addressing contextual/structural and biological intervention strategies (eg. topical microbicides or pre-exposure antiviral prophylaxis) still in urgent development.

\section{Acknowledgments}

We would like to thank Dr. Judy Auerbach for first thinking of and encouraging this comparison.

Judy Auerbach PhD Deputy Executive Director for Science and Public Policy San Francisco AIDS Foundation jauerbach@sfaf.org

This research uses data from Add Health, a program project designed by J. Richard Udry, Peter S. Bearman, and Kathleen Mullan Harris, and funded by a grant P01-HD31921 from the Eunice Kennedy Shriver National Institute of Child Health and Human Development, with cooperative funding from 17 other agencies. Special acknowledgment is due Ronald R. Rindfuss and Barbara Entwisle for assistance in the original design. Persons interested in obtaining data files from Add Health should contact Add Health, Carolina Population Center, 123 W. Franklin Street, Chapel Hill, NC 27516-2524 (addhealth@unc.edu). No direct support was received from grant P01-HD31921 for this analysis.

The Reproductive Health and HIV Research Unit (RHRU) South African Youth Survey was funded by the Kaiser Family Foundation. Dr Pettifor's time was supported by the Developmental Awards Program of the National Institutes of Health NIAID Sexually Transmitted Infections and Topical Microbicide Cooperative Research Centers (STI-TM CRC) grants to the University of Washington (AI 31448) and University of North Carolina (AI 31496).

Dr Pettifor had full access to all of the data in the study and takes responsibility for the integrity of the data and the accuracy of the data analysis.

\section{Appendix A: Description of survey sampling and compatibility}

Both surveys are nationally representative although they drew their samples from different populations of youth. The South African youth survey was household-based. The survey's sample was identified using a three-stage, disproportionate, stratified design. The 2001 national census was used as the sampling frame and enumeration areas (EAs) were designated as the primary sampling unit (PSU), creating a nationally representative sample of youth ages 15-24 in all nine provinces of South Africa. Households within selected EAs were then enumerated and one eligible youth per household was randomly selected to participate in the study. The sample was weighted to be representative of young people aged 15-24 years in South Africa for gender, age, race, province, and geography type.

The Add Health survey was based on individuals that were enrolled in school during $7^{\text {th }}-12^{\text {th }}$ grade in 1994, who were selected based on a stratified random sample of high schools in the United States that included an $11^{\text {th }}$ grade and an enrollment of at least 30 students. Stratification was based on region, urbanicity, school size and type, percent white and African American, grade span and curriculum type. Subsequent waves of data collection were collected by locating youth at their homes, regardless of their continued enrollment in school. The sample was weighted to be representative of a nationally-representative sample of American youth.

Since high school attendance is low among South African youth, capturing them in their homes was the most appropriate method for capturing a representative sample. In contrast, the majority of American youth attend high school. In 1995, there were 50,502,000 American students enrolled in public and private schools and the drop out rate for 16-24 year olds was $12 \%$. 
Therefore, using a school-based sample increased the likelihood of capturing a nationally representative sample. The surveys are thought to be compatible as they capture a group of youth that most represents the general population of that age in that country. As non-school attendees may exhibit riskier behaviors, their inclusion in the sample of US youth would likely skew estimates towards an even higher proportion of US youth engaging in risky sexual behaviors.

\section{Sources}

1. U.S. Department of Education; National Center for Education Statistics. Digest of Education Statistics, 2005. 2006 (NCES 2006-030), Chapter 1.

2. U.S. Department of Education; National Center for Education Statistics. The Condition of Education 2007. 2007 (NCES 2007-064), Indicator 23.

\section{Appendix B: Table of selected questions from each survey used to define variables}

\begin{tabular}{|l|l|l|}
\hline & RHRU: South Africa & Add Health: United States \\
\hline Variable & Question & Question \\
\hline $\begin{array}{l}\text { Ever had } \\
\text { vaginal sex }\end{array}$ & $\begin{array}{l}\text { Have you ever had vaginal sex with } \\
\text { someone (that is to say when the } \\
\text { penis was in vagina)? } \\
\text { Remember to clarify: 'This can } \\
\text { have been done to you or you could } \\
\text { have done it to someone' } \\
\text { Yes/no }\end{array}$ & $\begin{array}{l}\text { Have you ever had vaginal } \\
\text { intercourse? } \\
\text { inserts his penis into a } \text { woman's } \\
\text { vagina } \\
\text { Yes/no }\end{array}$ \\
\hline $\begin{array}{l}\text { Age at coital } \\
\text { debut }\end{array}$ & $\begin{array}{l}\text { Ifyes to above: How old were you } \\
\text { when you first did this? }\end{array}$ & $\begin{array}{l}\text { How old were you the first time you } \\
\text { had vaginal intercourse? }\end{array}$ \\
\hline $\begin{array}{l}\text { Number of } \\
\text { lifetime sexual } \\
\text { partners }\end{array}$ & $\begin{array}{l}\text { How many different people have } \\
\text { you had sexual intercourse with in } \\
\text { your whole lifetime? Remember } \\
\text { that sex is defined as anal } \text { or } \\
\text { vaginal sex }\end{array}$ & $\begin{array}{l}\text { With how many partners have you } \\
\text { ever had vaginal intercourse, even if } \\
\text { only once? }\end{array}$ \\
\hline $\begin{array}{l}\text { Age difference } \\
\text { with last sexual } \\
\text { partner }\end{array}$ & $\begin{array}{l}\text { What was your age when you first } \\
\text { had sex with most recent partner? } \\
\text { What was your partner's age when } \\
\text { you first had sex? }\end{array}$ & $\begin{array}{l}\text { For each relationship: "How old were } \\
\text { you when your sexual relationship } \\
\text { with partner began?" } \\
\text { How old was she/he? }\end{array}$ \\
\hline $\begin{array}{l}\text { Condom use at } \\
\text { last sex act } \\
\text { among those } \\
\text { who have ever } \\
\text { had sex) }\end{array}$ & $\begin{array}{l}\text { The last time you had sexual } \\
\text { intercourse, did you use a condom? } \\
\text { Yes/no }\end{array}$ & $\begin{array}{l}\text { The most recent time you had vaginal } \\
\text { intercourse did you/your partner use a } \\
\text { condom? } \\
\text { Yes/no }\end{array}$ \\
\hline
\end{tabular}

\section{References}

1. Pettifor A, Rees H, Kleinschmidt I, et al. Young people's sexual health in South Africa: HIV prevalence and sexual behaviours from a nationally representative household survey. AIDS. 2005; 19:1525-1534. [PubMed: 16135907]

2. Morris M, Handcock MS, Miller WC, et al. Prevalence of HIV Infection Among Young Adults in the United States: Results From the Add Health Study. Am J Public Health. Jun; 2006 96(6):10911097. [PubMed: 16670236]

3. Asthana A. Africa's fata sexual culture spreads AIDS. The Observer International. June 19.2005

4. Abrahams, B. Promiscuity in Africa. Suite 101.com. 2007.

http://aids-hivtreatment.suite101.com/article.cfm/promiscuity_in

5. Timberg C. Speeding HIV's Deadly Spread. Washington Post. March 2.2007 
6. Laga M, Schwartlander B, Pisani E, Salif Sow P, Carael M. To stem HIV in Africa, prevent transmission to young women. AIDS. 2001; 15(7):931-934. [PubMed: 11399966]

7. Gregson S, Nyamukapa CA, Garnett GP, et al. Sexual mixing patterns and sex-differentials in teenage exposure to HIV infection in rural Zimbabwe. Lancet. Jun 1; 2002 359(9321):1896-1903. [PubMed: 12057552]

8. Anderson RM, May RM, Boily MC, Garnett GP, Rowley JT. The spread of HIV-1 in Africa: sexual contact patterns and the predicted demographic impact of AIDS. Nature. Aug 15; 1991 352(6336): 581-589. [PubMed: 1865922]

9. The National Longitudinal Study of Adolescent Health. Questions About Field Work. http://www.cpc.unc.edu/projects/addhealth/faqs/aboutfieldwork\#1264. Accessed January 22, 2008

10. Chantala K, Kalsbeek W, Andraca E. Non-response in Wave III of the Add Health Study. 2004

11. Halperin DT, Epstein H. Concurrent sexual partnerships help to explain Africa's high HIV prevalence: implications for prevention. Lancet. Jul 3-9; 2004 364(9428):4-6. [PubMed: 15234834]

12. Carael, M. Sexual Behavior. In: Cleland, J.; Ferry, B., editors. Sexual behavior and AIDS in the developing world. Taylor and Francis; London: 1995.

13. Wellings K, Collumbien M, Slaymaker E, et al. Sexual behaviour in context: a global perspective. Lancet. Nov 11; 2006 368(9548):1706-1728. [PubMed: 17098090]

14. Buve A, Carael M, Hayes R, et al. The multicentre study on factors determining the differential spread of HIV in four African cities: summary and conclusions. AIDS. 2001; 15(suppl 4):S127S131. [PubMed: 11686461]

15. Garnett GP, Anderson RM. Factors controlling the spread of HIV in heterosexual communities in developing countries: patterns of mixing between different age and sexual activity classes. Philos Trans R Soc Lond B Biol Sci. Oct 29; 1993 342(1300):137-159. [PubMed: 7904355]

16. Luke, N. Cross-generational and Transactional Sexual Relations in Sub-Saharan Africa: A Review of the Evidence on Prevalence and Implications for Negotiation of Safe Sexual Practices for Adolescent Girls. International Center for Research on Women; Philadelphia: 2001.

17. Wood, K.; Jewkes, R. 'Dangerous' love: Reflections on violence among Xhosa township youth. In: Morrell, R., editor. Changing men in Southern Africa. University of Natal Press; Pietermaritzburg: 2001.

18. Varga C. How Gender Roles Influence Sexual and Reproductive Health Among South African Adolescents. Studies in Family Planning. 2003; 34(3):160-172. [PubMed: 14558319]

19. Miller KE, Farrell MP, Barnes GM, Melnick MJ, Sabo D. Gender/Racial Differences in Jock Identity, Dating, and Adolescent Sexual Risk. J Youth Adolesc. Apr; 2005 34(2):123-136. [PubMed: 16429602]

20. O'Donnell L, Myint UA, O'Donnell CR, Stueve A. Long-term influence of sexual norms and attitudes on timing of sexual initiation among urban minority youth. J Sch Health. Feb; 2003 73(2):68-75. [PubMed: 12643022]

21. Morris M. Sexual networks and HIV. AIDS. 1997; 11(suppl A):S209-S216. [PubMed: 9451987]

22. Pettifor AE, van der Straten A, Dunbar MS, Shiboski SC, Padian NS. Early age of first sex: a risk factor for HIV infection among women in Zimbabwe. Aids. Jul 2; 2004 18(10):1435-1442. [PubMed: 15199320]

23. Manning WD, Longmore MA, Giordano PC. The relationship context of contraceptive use at first intercourse. Fam Plann Perspect. May-Jun; 2000 32(3):104-110. [PubMed: 10894255]

24. Greenberg J, Magder L, Aral S. Age at first coitus. A marker for risky sexual behavior in women. Sex Transm Dis. Nov-Dec; 1992 19(6):331-334. [PubMed: 1492259]

25. Duncan ME, Tibaux G, Pelzer A, et al. First coitus before menarche and risk of sexually transmitted disease. Lancet. Feb 10; 1990 335(8685):338-340. [PubMed: 1967779]

26. Asiimwe-Okiror G, Opio A, Musinguzi J, Madraa E, Tembo G, Carael M. Change in sexual behaviour and decline in HIV infection among young pregnant women in urban Uganda. AIDS. 1997; 11(14):1757-1763. [PubMed: 9386811]

27. Genuis SJ, Genuis SK. Primary prevention of sexually transmitted disease: applying the ABC strategy. Postgrad Med J. May; 2005 81(955):299-301. [PubMed: 15879042] 
28. Hallett TB, Gregson S, Lewis JJ, Lopman BA, Garnett GP. Behaviour change in generalised HIV epidemics: The impact of reducing cross-generational sex and delaying age at sexual debut. Sex Transm Infect. Feb 21.2007

29. Pettifor A, Measham D, Rees H, Padian N. Sexual power and HIV risk, South Africa. Emerging Infectious Diseases. 2004; 10(11):1996-2004. [PubMed: 15550214]

30. Wood K, Maforah F, Jewkes R. "He forced me to love him": Putting violence on adolescent sexual health agendas. Social Science \& Medicine. 1998; 47(2):233-242. [PubMed: 9720642]

31. South African Department of Health. South African Demographic and Health Survey 1998. South African Department of Health; Pretoria: 2001.

32. Auvert B, Ballard R, Campbell C, et al. HIV infection among youth in a South African mining town is associated with herpes simplex virus-2 seropositivity and sexual behaviour. AIDS. 2001; 15:885-898. [PubMed: 11399961]

33. Pettifor A, Kleinschmidt I, Levine J, et al. A community based study to examine the effect of a youth HIV prevention intervention on young people age 15-24 in South Africa: results of a baseline survey. Tropical Medicine and International Health. 2005; 10(10):971-980. [PubMed: 16185231]

34. Miller WC, Ford CA, Morris M, et al. Prevalence of chlamydial and gonococcal infections among young adults in the United States. Jama. May 12; 2004 291(18):2229-2236. [PubMed: 15138245]

35. Auvert B, Taljaard D, Lagarde E, Sobngwi-Tambekou J, Sitta R, Puren A. Randomized, controlled intervention trial of male circumcision for reduction of HIV infection risk: the ANRS 1265 Trial. PLoS Med. Nov.2005 2(11):e298. [PubMed: 16231970]

36. Bailey RC, Moses S, Parker CB, et al. Male circumcision for HIV prevention in young men in Kisumu, Kenya: a randomised controlled trial. Lancet. Feb 24; 2007 369(9562):643-656.

[PubMed: 17321310]

37. Gray RH, Kigozi G, Serwadda D, et al. Male circumcision for HIV prevention in men in Rakai, Uganda: a randomised trial. Lancet. Feb 24; 2007 369(9562):657-666. [PubMed: 17321311]

38. National Hospital Discharge Survey. 1999. http://www.cdc.gov/nchs/about/major/hdasd/nhds.htm. Accessed Jan 3, 2007 

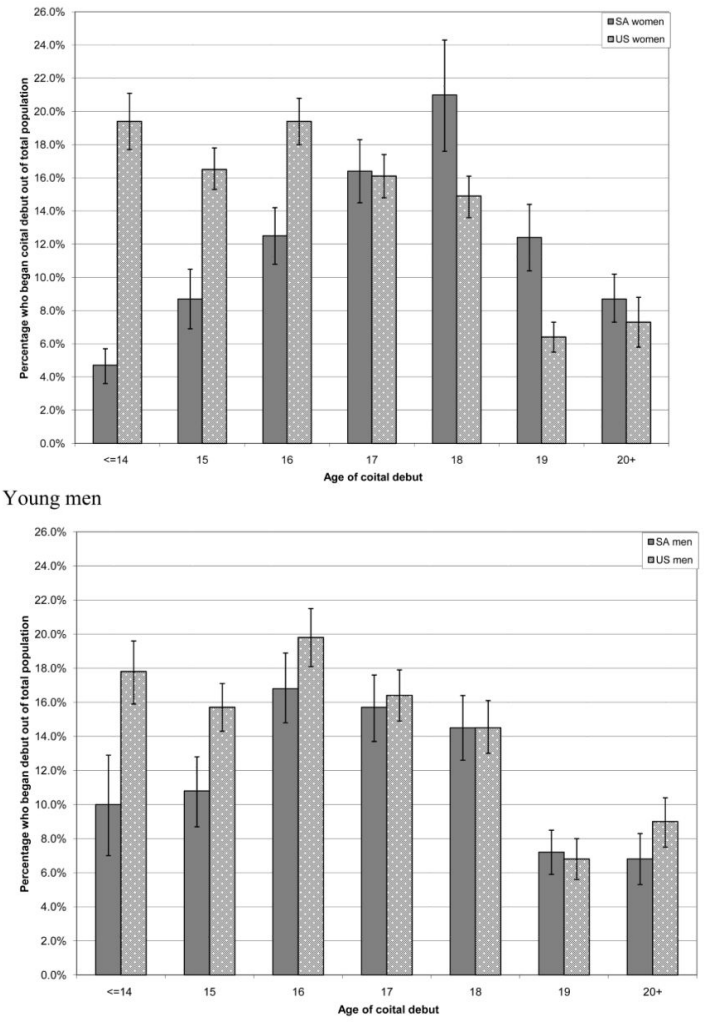

Figure 1.

Age of first sex for young women and young men ages 18 to 24 years in South Africa (SA) and the United States (US). 

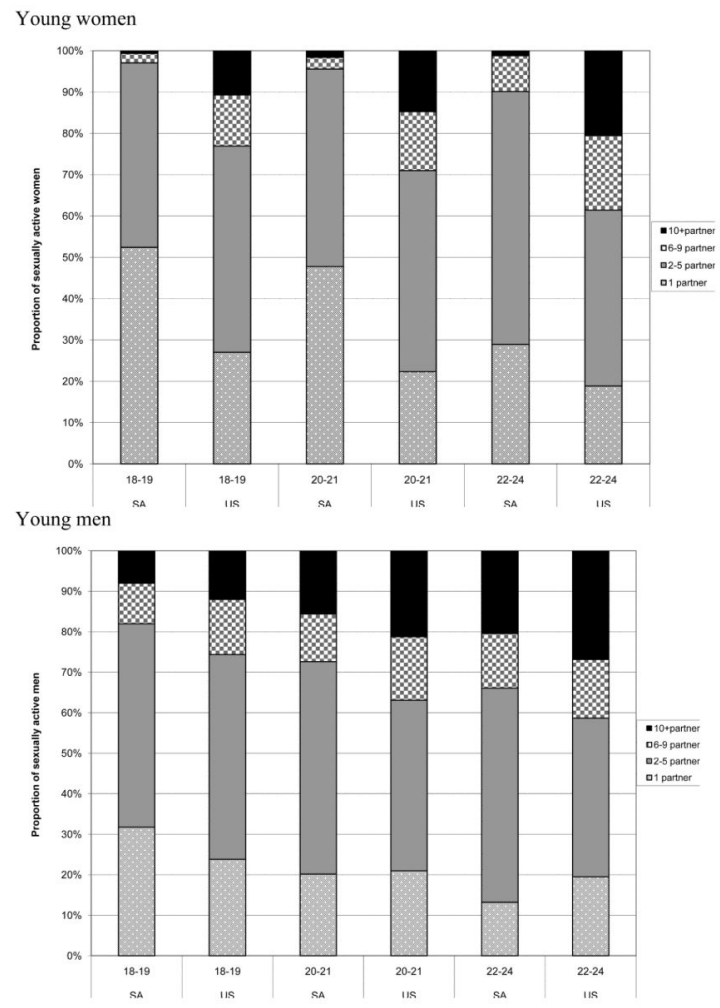

Figure 2.

Number of lifetime sexual partners for sexually experienced young women and young men ages 18 to 24 years in South Africa (SA) and the United States (US) 


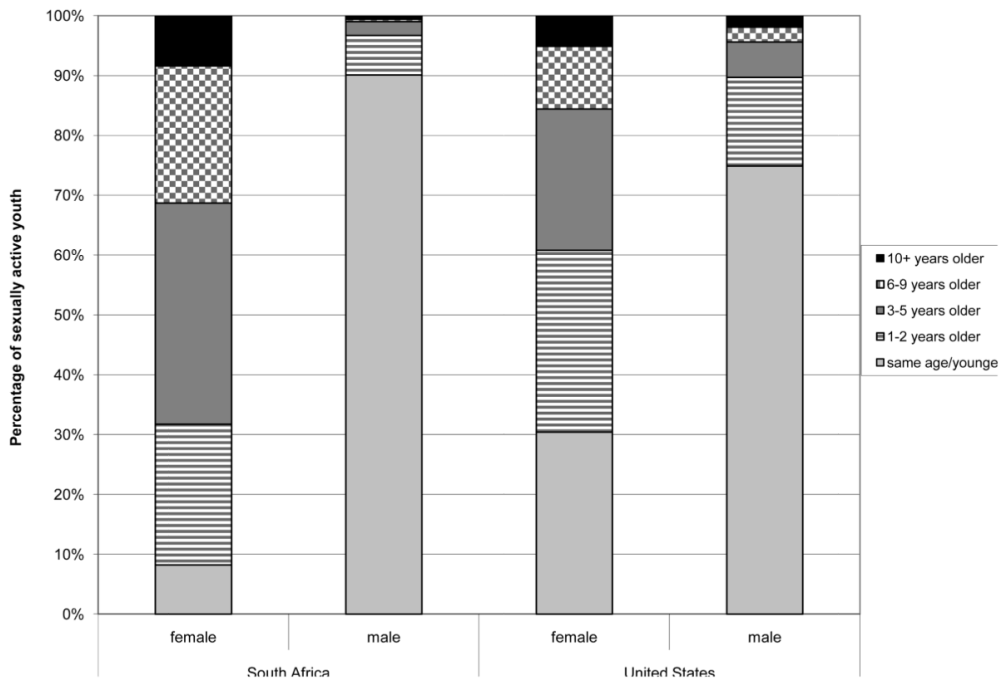

Figure 3.

Age difference with most recent partner for young women and young men ages 18 to 24 years in South Africa (SA) and the United States (US) 
